\title{
The Extra English Learning Experiences Reduce Negative Transfer in Syntactical Patterns Among Chinese Students' English Writing in SLA Limitedly
}

\author{
Xinhui Zhang ${ }^{1, *}$ \\ ${ }^{1}$ School of Arts, Languages and Cultures, The University of Manchester, Manchester, M13 9PL, UK. \\ *xinhui.zhang@student.manchester.ac.uk.
}

\begin{abstract}
In China, many students pay attention to extracurricular English practice to improve their English writing, and many leave mainland China and receive English-teaching mode in university. Although plenty of efforts are spent into English learning, Chinese negative transfer still influences students' English writing inevitably. This article gathered data from 32 college students from China, 16 of them studying in mainland with Chinese as their teaching language and the others studying in other regions with English as their teaching language, and compared their performance in English writing. Considering their learning environment and individual English study modes, it turned out that the extra English learning experiences can help reduce students' negative transfer in syntactical patterns but the effect is limited. This contradicts many people's belief that studying abroad and English-teaching environment can shape a perfect English second language learner to a large extent.
\end{abstract}

Keywords: negative transfer, Chinese students' English writing, English learning experiences, syntactical pattern.

\section{INTRODUCTION}

In the Second Language Acquisition (SLA), language transfer is viewed as a broad phenomenon. Jarvis \& Pavlenko defines language transfer as the influence of one language to another, which is embodied in two types: positive transfer and negative transfer [1]. Perkins \& Salmon defined these two categories: positive transfer contributes to learning a foreign language learning while negative transfer undermines it [2].

There are various elements causing language transfer. Some periods in foreign culture may reshape the cultural cognition of speakers, influencing their habits and talking patterns. The experience of some international students can reveal this point. Their daily discourse may include both their L1 and L2, which they use when studying. Their sentence structure of L1 may be influenced by L2, which causes unnatural and ungrammatical L1 expressions. These morphological and syntactical phenomena, together with phonetics, phonology, and pragmatics, are the manifestations of cross-linguistic transfer.
Regardless of the proficiency level of English, L2 learners can never escape the effect of L1 [3]. In China, as the number of students studying abroad and the importance of English study increases continuously, there are many researches on the negative transfer of Chinese among Chinese students. Liu talked about the negative transfer among Chinese Students' English writing at vocabulary, sentence structure, and discourse levels [4]. The author focused on the misallocation, which involves the preposition in the lexical level, and found out that the lack of coherence is the main structural error in the collected data. Liu believed that the insufficient attention paid to the Chinese negative transfer could lead to more mistakes [4]. Guo et al. confirmed the influence of Chinese on English learning in their separate studies [5]. They asked 54 students to write a 100-150 paper within 30 minutes and then used Error Analysis to analyze the data in lexical level and syntactical level. Their study showed that the direct translation from Chinese to English has more or less become the teaching techniques in senior middle schools in China. Shi further introduced types of Chinese negative transfer in the view of pronunciation, vocabulary, syntax, grammar, pragmatics, and culture 
[6]. The categorization echoes the chapter Linguistic Transfer in Crosslinguistic Influence in Language and Cognition by Jarvis \& Pavlenko [1]. Shi provided measures to decrease negative transfer, such as thinking in an English way and suggesting teachers teach learning methods instead of only delivering knowledge. Shi and Guo et al. suggested students learn more about English culture $[5,6]$. Chan investigated the syntactic transfer of Chinese among Hong Kong Chinese students and found out five error types [7]. The study revealed that surface Chinese sentence structure influenced participants' English production, and L1 can still influence highproficiency learners.

These studies and results reveal the frequent error types of Chinese students. Most Chinese students face extensive enrollment pressure, no matter which geographical regions they live in China. The phenomenon indicates that the main purpose of Chinese students learning English is to obtain high marks in the examination. Although some parents and students view English intelligence as necessary in personal development, the motivation for better examination performance exceeds all the other elements. Though the research gathers materials and provides suggestions on Chinese students learning English as a second language, the effectiveness, and feasibility of the suggestions are doubtful because many schools only focus on the score results, and learning English culture is far slower than directly teaching English grammar. Many researches have discussed the types of negative transfer and have confirmed the influence of Chinese on learning English, but they ignore the elements from learners' side in learning effect. As most Chinese students' English learning experiences at school are similar under the compulsory education system, their extra English learning experiences and the corresponding influence on their English capacity need attention. Although plenty of social factors influence the study result of English learners, this paper focuses on the influence of Chinese learners' extra English learning experiences and its impacts on the negative transfer of syntactical patterns among Chinese students. The external manifestation of extra English learning experiences is personal reading and listening input, including frequency and duration each time. Studying abroad has become an increasing trend in China. Students studying in English and nonEnglish environments are invited to collect data.

\section{METHODOLOGY}

The data from all the participants include their personal information, learning experiences, traveling abroad experiences, and their original English essays.
In total, 54 invitations were sent, and 38 responses were received, of which 32 are valid. All the valid responses are equally from boys and girls, and 16 of them receive undergraduate education in the mainland, China (they will be named "mainland students" below) while others are in Hong Kong, China, and other regions (correspondingly, the students will be called "international students"). All the data are collected via the online questionnaire.

The negative transfer in syntactical patterns of English essays from participants in the analysis object. The analysis of the error type is divided into three parts: punctuation usage, words, and sentence structure.

\section{RESULTS}

The errors of different types and the appearance of various sentence structures are counted based on the participants' essays, and all participants answered a questionnaire related to their study experience. The results will be divided into three parts to elaborate, including errors, number of appearances, and personalized data. The figures in percentage are accurate to one decimal place unless further explanation.

\subsection{Errors}

There is almost no difference in error types among Chinese students with various studying experiences. All the errors are divided into three types, punctuation and possessive case, words, and sentence structure.

\subsubsection{Punctuation and possessive case}

Despite the almost identical error types, the number of mistakes among international and mainland students varies. The first category is about comma usage. As shown in table 1 , the total number of errors of international students is about $15 \%$ more than that of mainland students, with 71 times and 62 times respectively. The students remain punctuation habits in Chinese. They forgot to use a comma to separate noun phrases and linked sentences with comma. Also, they did not add a comma after an adverbial phrase. Sometimes they used comma more than needed, which caused redundancy. When it comes to the number of possessive case errors, international students' data is also higher than mainland students, as shown in table 2. This shows the influence of Chinese negative transfer because in Chinese, the possessive case is shown by adding Chinese characters but not the apostrophe. Thus, affected by Chinese, many students lost the apostrophe in possessive case. 
Table 1. Number of punctuation errors

\begin{tabular}{|c|c|c|c|c|c|}
\hline \multicolumn{5}{|c|}{ CategoryPunctuation } & \multirow[t]{2}{*}{ Total number } \\
\hline Students & To separate & Adverbial phrases & Appositive & Redundancy & \\
\hline $\begin{array}{l}\text { International } \\
\text { students }\end{array}$ & 46 & 11 & 2 & 12 & 71 \\
\hline Mainland stu & 29 & 10 & 0 & 23 & 62 \\
\hline
\end{tabular}

Table 2. Number of possessive case errors

\begin{tabular}{|l|l|}
\hline Students & Category Possessive case \\
& \\
\hline International students & 5 \\
\hline Mainland students & 4 \\
\hline
\end{tabular}

\subsubsection{Words}

\subsubsection{Noun and verb}

International students totally had five more noun mistakes and eleven more verb mistakes than mainland students, according to table 3 . All four errors of pronouns from international students are the same. They should use its to refer to the singular noun, while they all use their. In the case of common noun plural, there are six more mistakes among international students. (1.2) a. is extracted from one international student's essay, and (1.2) b. is from one mainland student, where the mistakes are italic. As there is no noun plural or verb inflection in Chinese, which means no matter the number of the noun, the noun is the same form, and no matter the tense the subject, and the voice are, the verb is always the same form, students can easily get lost when writing in English. Students judge the singular and plural based on the context in Chinese. However, that leads to mistakes in English. Students do not consider verb inflection in Chinese. Accordingly, they went into chaos in English writing, and all these show Chinese negative transfer.

Table 3. Number of noun and verb errors

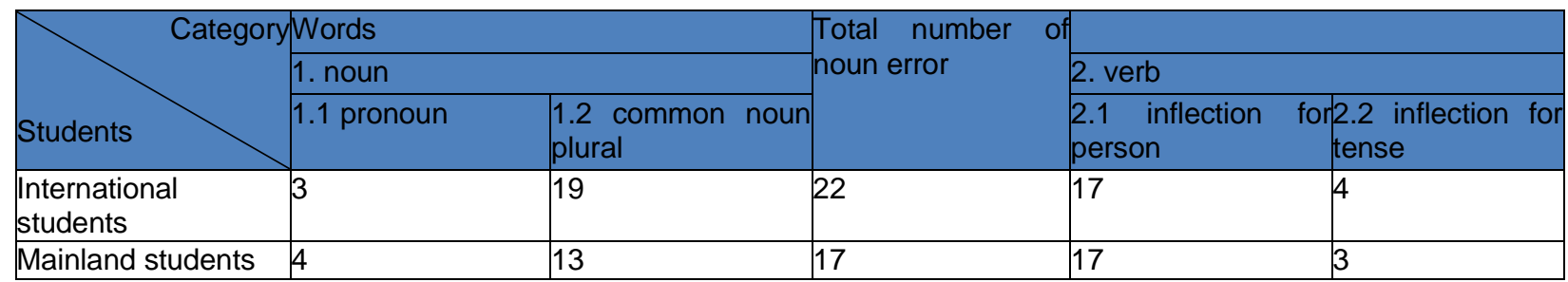

Table 4. Number of noun and verb errors (continued)

\begin{tabular}{|c|c|c|c|c|c|}
\hline Categc & Words & & & & Total number o \\
\hline & 2. verb & & & & verb error \\
\hline Students & $\begin{array}{l}2.3 \text { inflection } \\
\text { related to voice }\end{array}$ & $\begin{array}{l}2.4 \text { inflection } \\
\text { related to -ing } \\
\text { participle }\end{array}$ & $\begin{array}{l}2.5 \text { particle of } \\
\text { phrasal verb }\end{array}$ & $\begin{array}{l}2.6 \text { other wrong } \\
\text { forms }\end{array}$ & \\
\hline $\begin{array}{l}\text { International } \\
\text { students }\end{array}$ & 4 & 4 & 14 & 0 & 43 \\
\hline Mainland students & 2 & 3 & 6 & 1 & 32 \\
\hline
\end{tabular}

(1.2) a. rules is also the stepping stone towards a stable and prosperous countries.

b. so we must compare the mean of each treatments.

The number of verb errors outweighs that of noun errors. One of the main verb error types is the verb inflection for person. It is related to third-person singular, where some participants used the plural form. One noted point about the inflection for person is the person state of special plural variation of noun, as shown in (2.1) a., a sentence from one mainland student. In most cases, the verb of "graffiti" reflects the 3-third person singular, while the writer used plural reflection. Another point is about the verb inflection of noun phrases and clauses. (2.1) b and c are from the same international student. In both sentences, the italic verbs should be single form. However, the student used the plural form probably due to the influence of the noun before the predicate is plural.

(2.1) a. ... if there are some graffiti have not been washed off... 


\begin{abstract}
b. The idea of the tariffs are related to what was mentioned above

c. what the Mercantilists "fears" are very

beneficial for domestic markets
\end{abstract}

The wrong verb inflection for tense is reflected in wrong verb conjugation, such as we've know in (2.2) from a mainland student's essay. The error of verb inflection related to voice means that a verb should change to its past participle form in the passive voice, while it remains its original lexeme form, that the inflection lacks the auxiliary verb to construct the passive voice, which causes errors, or that the writer chooses the wrong voice. As lessen shown in (2.3) a. from an international student, it should be in its past participle form, but it keeps its infinitive. As have born shown in (2.3) b. from a mainland student, the necessary auxiliary verb "been" is missing, which causes the mistake. It's worth noting that the other error of inflection related to voice from mainland students also shows the lack of copula. One error represents the incorrect voice type, as shown in (2.3) c. The italic "comparing" should be corrected as "compared" because the subject "I" is passively compared to others but not the active implementer of "compare". In other words, the phrase in the declarative order is "compare I (me) and other students". When "I" is in front of "compare" and becomes the subject, the verb "compare" should be in past participle form "compared", which indicates passive voice, but not "comparing", which indicated active voice.

(2.2) We've know that the eigenvalue of $A$ is 1 or 0.

(2.3) a. ... ionizing radiation, airless, gravityless" and cannot be easily lessen by the technology in this age.

b. Young people of this generation have born in such good times...

c. Also, I have more understanding about Hong Kong's culture comparing to other mainland students.

One of the cases related to -ing participle is (2.4). The verb after the preposition than should be in -ing participle, while the mainland student maintains the lexeme be.

... any tree with dignity would rather be crushed to pave the way for pedestrians than be suppressed by other trees.

The phrasal verb particle is also a main error type for both international and mainland students, which takes about $32.6 \%$ and $16.2 \%$ of total verb errors. The results reveal that international students make about twice as many phrasal verbs mistakes as mainland students do. When it comes to specific mistakes, some particles are deleted, and others are misused. Among international students, 7 out of 14 are deleted, and for mainland students, the ratio is also 3 out of 6 . For example, a mainland student wrote (2.5), which shows a deletion of preposition to in the phrase "lead to sth". The finding echoes Liu who found writing errors among English and non-English majors mostly involved wrong collocation of words with preposition [4].

Despite an objective fact, it is always subjective to build a connection between them, leading weak relation between the two.

The only left verb error of data is difficult to categorize, and it is set as other wrong forms. The copula is missing in this case. As seen in (2.6) a., before the adjective unreliable, a copula is is missed. ... the way that dream reflected so many
impressions was not clear, and the
predominant clue, cocaine, unreliable.

\subsubsection{Adjective and adverb}

International students make more than twice adjective and adverb errors as mainland students. Apart from errors in comparative inflection, one international student used an adjective to modify another adjective as shown in (3.1). The wrong word sequence of adjective also appears in essays of international and mainland students. For example, a mainland student wrote (3.2) where most and three should be reversed as the three most. The unique error among international students is that one student used an adverb to modify a noun.

Table 5. Number of adjective and adverb errors

\begin{tabular}{|c|c|c|c|c|}
\hline \multirow[b]{3}{*}{ Students } & Wo & & & \multirow{3}{*}{$\begin{array}{l}\text { Total number of } \\
\text { adjective and adverb } \\
\text { error }\end{array}$} \\
\hline & \multicolumn{2}{|c|}{ 3. adjective } & \multirow{2}{*}{$\begin{array}{l}\text { 4. adverb } \\
4.1 \text { coordinate with noun }\end{array}$} & \\
\hline & $\begin{array}{l}3.1 \\
\text { infle }\end{array}$ & comparative 3.2 other wrong forms & & \\
\hline International students & 3 & \begin{tabular}{l|l} 
& 3 \\
\end{tabular} & 1 & 7 \\
\hline Mainland students & 2 & 1 & 0 & 3 \\
\hline
\end{tabular}


$\ldots$ the professor sheds light on the potential deleterious consequences of implementing tax.

(3.2) We can find that the most three important factors of well-being are education, environment, and health indicators.

\subsubsection{Preposition and article}

The use of prepositions and article is a challenge for both international and mainland students. Compared with former data of total number in table 4 and 5 , the total number in table 6 surged increasingly. Many students chose prepositions at random, showing the feasibility of substitutability of various preposition in Chinese, and international students make $30.7 \%$ more mistakes than mainland students in this aspect. Two examples are shown in (5.1) and (5.2), from an international student and a mainland student. The article is the most frequent error type of all and mainland students do not perform as well as international peers regarding this, with two more errors. The specific type includes definite and indefinite article deletion, redundancy, and substitution. There are six cases in total where "an" is substituted for "a" and vice versa. The examples of (6.1) and (6.2) from an international student are representatives of deletion and substitution. The italic "the" of (6.1) is deleted in the original sentence. The reason for errors in article is probably that people are not aware of using article in Chinese, which means it is not a must to add an article before a noun in Chinese and many omit it. From the data, it is obvious that the Chinese transfer in article greatly influences Chinese students' English writing.

Table 6. Number of preposition and article errors

\begin{tabular}{|c|c|c|c|}
\hline \multicolumn{3}{|c|}{ Category|Words } & \multirow{2}{*}{$\begin{array}{l}\text { Total number of preposition } \\
\text { and article error }\end{array}$} \\
\hline Students & 5. preposition & 6.article & \\
\hline International students & 17 & 50 & 67 \\
\hline Mainland students & 13 & 52 & 65 \\
\hline
\end{tabular}

... sometimes I still feel a distance with the local students ...

(5.2) Besides, we can gain inspiration of life from the humanities.

(6.1) ... many of them do not spend up all the money till the end of the month.

(6.2) the College Financing Program (the CFP), which is $a$ easy-to-use applet that provide personal lowrisk financing service for college students.

\subsubsection{Sentence structure}

\subsubsection{Subject-predicate consistency and inversion}

As shown in table 7. It is worth noting that although the total number of mistakes of international students is slightly over that of mainland students, the error of international students exists only in subject-predicate consistency, excluding inversion.

The main reason for making mistakes is that the subject or the reference of the preposition phrase is not the same as the subject of the main clause. In Chinese, this is reasonable because people can understand from the context, but in English, it is ungrammatical. For example, in (7.1) a. written by an international student, "the Bangladesh government and UGC" is not "a British-style education system country". Another reason of mistakes is the incorrect verb form, such as (7.1) b. from an international student's essay where "sell" should be "selling" as an adverbial modifier.
The inversion means subject-predicate inversion whose errors only appear among mainland students, as shown in (7.2). In (7.2) a., the whether clause should be in declarative sequence while the sentence remains interrogative sequence. In (7.2) b., the inversion structure is correct while the conjugation of "exist" should be "exist" but not "existed" because the auxiliary verb "did" is in the front, suggesting the verbs after it should be in their infinitive.

Table 7. Number of subject-predicate consistency and inversion errors

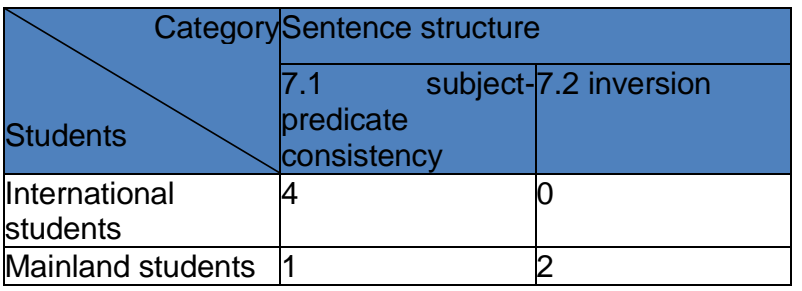

(7.1) a. In general, as a British-style education system country, the Bangladesh government and UGC work together and make lots of differences in this country's education.

b. Sell packaged fixed weights cooking ingredients according to popular recipes, instead of buying various types of ingredients, they just need to buy the specific packages of meals they want.

(7.2) a. This leads to an argument on whether should China fully open the permission to the external Internet. 
b. ... suggesting that there did bees existed on earth 200 million years ago.

\subsubsection{Coordination}

When sentences are in coordination with each other, none of them is affiliated with one another and equal. The mistakes related to coordination are set as two types: lack verb and lack conjunction, and table 8 shows the times of error.

Most students wrongly use conjunctions whose function is to join words, phrases, or sentences together. At the level of syntax, one conjunction should link two predicates, one before it and the other after it. However, some students use the conjunction in one simple or complex sentence without linking two predicates. No matter which of the cases above appears, it is set as " 8.1 coordination: lack verb". As shown in (8.1), if the writer used $s o$ as a conjunction, it should be between "occur" and "people". However, the student used so at the beginning of the sentence.

The other case, lacking conjunction, indicates that students use other words or commas instead of conjunctions to link two sentences. As shown in (8.2), the student used a comma to link two sentences. Technically, a conjunction, such as and, should be inserted between these two sentences so that the sentence conforms to the grammatical rules.

Table 8. Number of coordination errors

\begin{tabular}{|l|l|l|}
\hline \multirow{2}{*}{ Category } & Sentence structure \\
\cline { 2 - 3 } Students & $\begin{array}{l}8.1 \text { coordination: } \\
\text { lack verb }\end{array}$ & $\begin{array}{l}8.2 \text { coordination: } \\
\text { lack conjunction }\end{array}$ \\
\hline $\begin{array}{l}\text { International } \\
\text { students }\end{array}$ & 11 & 7 \\
\hline Mainland students & 9 & 6 \\
\hline
\end{tabular}

(8.1) In more serious cases, depression may even occur. So people often look for some way to reduce stress, ...

(8.2) sharing discoveries is not always a good thing to human society, it may be unreasonable and irrational ...

\subsubsection{Subordination}

According to the data, the detected error type of subordination is adverbial clause of cause which is led by because. Both international and mainland students made mistakes but not frequently. Only one error and two errors are detected respectively among international and mainland students, as shown in table 9.

Some students use the sub-clause as an independent sentence. As shown in (9.1) a., written by an international student, the italic "because" should be linked by a comma after the previous there-be sentence to elaborate the reason. By contrast, the student used "because" to lead a separate sentence. A mainland student made the same mistake as shown in (9.1) b.

(9.1) a. There is also a good solution through enough training by businesses. Because every company has its own corporate culture, which is totally new for the juniors.

b. But this argument has been met with a degree of opposition. Because it misses many important factors that directly impact happiness and the general health of a country.

Table 9. Number of subordination errors

\begin{tabular}{|l|l|}
\hline & \multicolumn{1}{c|}{ Category Sentence structure } \\
\cline { 2 - 2 } Students & $\begin{array}{l}9.1 \text { subordination: adverbial } \\
\text { clause }\end{array}$ \\
\hline International students & 1 \\
\hline Mainland students & 2 \\
\hline
\end{tabular}

\subsubsection{4. -ing participle}

As -ing participle itself functions as part of syntactic structure, such as subject, attributive and complement, ing participle is categorized under 3.1.3. Sentence structure. This account must be approached with some caution because the only case is from an international student. Based on the data shown in (10.1), it is not essential to use "taking" because take... as examples is already a verb phrase, and it can support as a grammatical sentence. It is thought that the phrase is one of the most frequent ones taught at school. In view of the writer, an international student, who probably uses English more often than a mainland student, the result of making this error is unexpected.

Table 10. Number of -ing participle errors

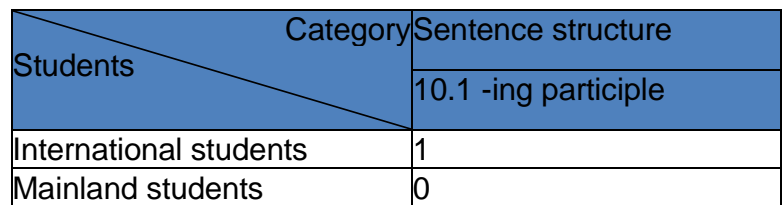

(10.1) Taking quantum mechanics and aerodynamics as examples, there is no doubt that... .

This section has calculated 10 error types in total, including 19 sub-types. The total number of all errors of international and mainland students are shown below in table 11 where international students have almost $10 \%$ more errors than mainland students. However, the total word counts of two groups are not identical. Some may believe the more errors are due to the more words involved. Thus, the total words and the error frequency are shown in table 12. The frequency of students making errors is equal to the total number of errors divided by the total number of word accounts (the frequency is accurate to three decimal places to avoid identical data in this column). Thus, the frequency reflects the density of error. The higher the frequency is, the more probability of 
making errors is in the context with the same word account of two groups. According to table 12, it is indicated that mainland students have a very slightly more possibility of making errors than international students as the frequency of mainland students $(1.442 \%)$ is $0.05 \%$ more than that of international students.

Table 11. The total number of all errors

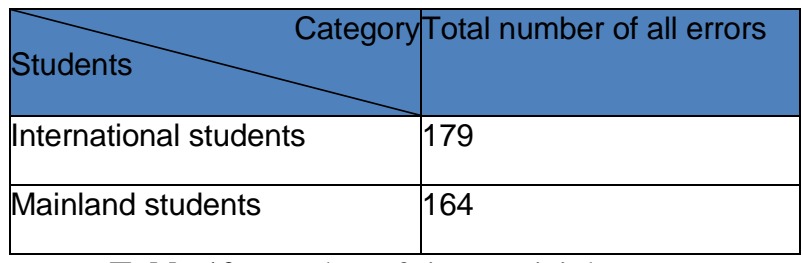

Table 12. Number of -ing participle errors

\begin{tabular}{|l|l|l|}
\hline Students & & \\
\hline $\begin{array}{l}\text { International } \\
\text { students }\end{array}$ & 12856 & $1.392 \%$ \\
\hline Mainland students & 11370 & $1.442 \%$ \\
\hline
\end{tabular}

\subsection{Number of appearances}

The calculation of the number of appearances includes the number of the error because the mistake also reflects students' intention of using the sentence structure. In order to clarify the results, the figures in table 13-17 include the number of appearances, their corresponding percentage, the difference value between the percentage of appearances of international students and that of mainland students. To be more specific, the figure in front of the forward slash is the absolute number of cases and that after the forward-slash is the percentage of the case. Furthermore, the difference value equals the percentage of appearances of international students subtracts that of mainland students. The minus figure of the difference value is meaningful accordingly because it elaborates the percentage of appearances of international students does not surpass that of mainland students.

According to the data, mainland students use all listed sentence structures approximately as many as international students to use the listed sentence structures, with only three more cases. Although the total number is similar, the range of the percentage of appearances of international students is $21.2 \%$, whereas that of the percentage of appearances of mainland students is $26.8 \%$, more than five percentage points higher.

Turning to the most frequent sentence type, passive voice as the predicate is the most presented for international students $(21.5 \%)$ and mainland students $(27.1 \%)$. The number of the case of mainland students is 5.6 percent point higher than that of the case of international students. These data, together with the range of the percentage of appearances, must be interpreted with caution because mainland students have a larger range and higher percentage of one particular sentence structure. These records may imply that mainland students are more likely to stick to one sentence type instead of applying various types to increase sentence diversity.

Even though the discrepancy of percentage of the most frequent sentence type is great, in terms of the rarest sentence type, it seems that both international students and mainland students are not favour of using if/whether of interrogative sub-clause as subject, only one case appearing respectively.

Having discussed the most and least preferred sentence structure of international and mainland students, it is also necessary to compare the difference in the percentage of appearances of the two groups. As shown in table 13-16, the maximum in the difference row is $7.0 \%$, and the minimum is $-5.9 \%$. These figures suggest that international students tend to use passive voice as a non-predicate more than mainland students. By contrast, mainland students prefer more declarative sub-clause: that as object than international students.

Table 13. The number and its percentage of appearances

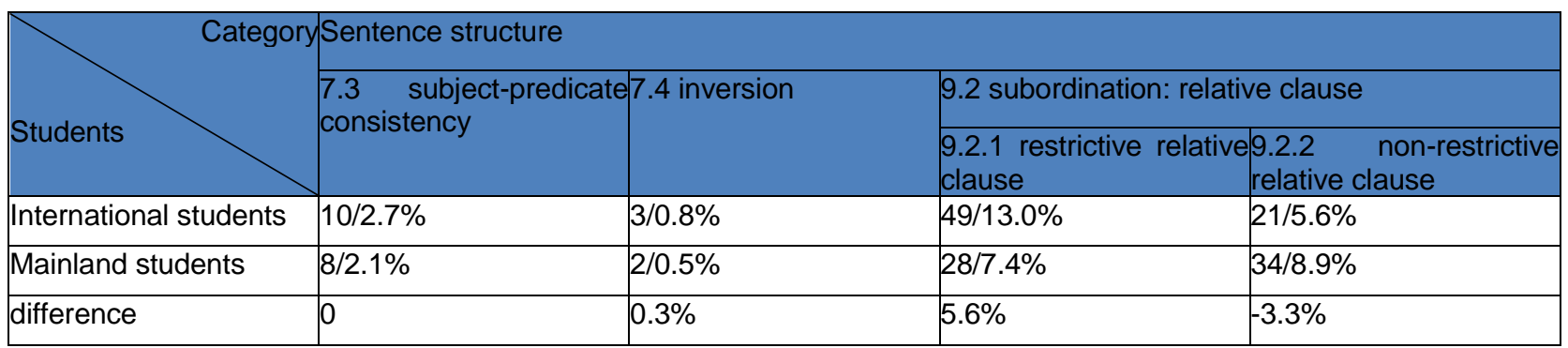


Table 14. The number and its percentage of appearances (continued 1)

\begin{tabular}{|c|c|c|c|c|}
\hline \multicolumn{5}{|c|}{ CategorySentence structure } \\
\hline & \multicolumn{2}{|l|}{10.2 -ing participle } & \\
\hline & 10.2.1 as subject & $\begin{array}{l}10.2 .2 \\
\text { attributive/complement/ } \\
\text { modifier }\end{array}$ & $\frac{1 \text { I passive vuice }}{\text { is } 11.1 \text { as predicate }}$ & 11.2 as non-predicate \\
\hline Students & $7 / 1.9 \%$ & $17 / 4.5 \%$ & $81 / 21.5 \%$ & $52 / 13.8 \%$ \\
\hline Mainland students & $19 / 5.0 \%$ & $27 / 7.1 \%$ & $103 / 27.1 \%$ & $26 / 6.8 \%$ \\
\hline difference & $-3.1 \%$ & $-2.6 \%$ & $-5.6 \%$ & $7.0 \%$ \\
\hline
\end{tabular}

Table 15. The number and its percentage of appearances (continued 2)

\begin{tabular}{|c|c|c|c|c|}
\hline \multirow[b]{3}{*}{ Students } & \multicolumn{4}{|c|}{ ySentence structure } \\
\hline & \multicolumn{2}{|c|}{12 declarative sub-clauses: -that clause } & \multirow{2}{*}{$\begin{array}{l}13 \text { extraposed subject } \\
\text { sclause: -that }\end{array}$} & \multirow[t]{2}{*}{ 14 there be } \\
\hline & 12.1 as object & $\begin{array}{l}12.2 \text { as } \\
\text { subject/noun/adjective } \\
\text { complement/predicate }\end{array}$ & & \\
\hline International students & $41 / 10.9 \%$ & $20 / 5.3 \%$ & $16 / 4.2 \%$ & $32 / 8.5 \%$ \\
\hline Mainland students & $64 / 16.8 \%$ & $5 / 6.3 \%$ & $20 / 5.3 \%$ & $26 / 6.8 \%$ \\
\hline difference & $-5.9 \%$ & $-1.0 \%$ & $-1.1 \%$ & $1.7 \%$ \\
\hline
\end{tabular}

Table 16. The number and its percentage of appearances (continued 3)

\begin{tabular}{|c|c|c|c|c|}
\hline \multirow[b]{3}{*}{ Students } & Sentence structu & & & \\
\hline & \multicolumn{4}{|c|}{15 interrogative sub-clause } \\
\hline & $\begin{array}{l}15.1 \text { if/whethe } \\
\text { subject) }\end{array}$ & (as 15.2 if/whether & (as 15.3 wh- (as subject) & 15.4 wh- (as object) \\
\hline International students & $1 / 0.3 \%$ & $4 / 1.1 \%$ & $8 / 2.1 \%$ & $15 / 4.0 \%$ \\
\hline Mainland students & $1 / 0.3 \%$ & $4 / 1.1 \%$ & $6 / 1.6 \%$ & $7 / 1.8 \%$ \\
\hline difference & 0 & $0 \%$ & $0.5 \%$ & $2.2 \%$ \\
\hline
\end{tabular}

Table 17. The total number of percentage of appearances

\begin{tabular}{|c|c|}
\hline Students & $\begin{array}{ll}\text { Total number and } \\
\text { percentage of appearances }\end{array}$ \\
\hline International students & $377 / 100 \%$ \\
\hline Mainland students & $380 / 100 \%$ \\
\hline
\end{tabular}

\subsection{Personalized data}

This section provides data about participants' personal experiences to help better analyze and understand their writing performance. In general, international students are slightly more confident about their English level and tend to engage in English study more intensively than mainland students. As shown in table 18, they graded themselves respectively 3.1 and 2.7 out of 5 .

International students are comparatively less active compared to the total days, frequency, and time span of summer/winter camp and school, as shown in table 19 and 20 . The total time of their summer/winter camp/school is equal to their English teaching time. International students only received 166.3 days of English teaching in total, much less than 240 days of mainland students. On average, each of the mainland students spent almost five more days in their camps and schools. However, for each time, international students spent more time on the study, and each international student spent 0.2 more days each time than mainland students.

Table 18. Self-rating on English level

\begin{tabular}{|l|l|}
\hline Students & CategoryAverage score \\
\hline International students & 3.1 \\
\hline Mainland students & 2.7 \\
\hline
\end{tabular}

Table 19. Education in English on summer/winter camp, summer/winter school

\begin{tabular}{|l|l|}
\hline \multicolumn{1}{|c|}{ Category } & Days in total \\
\hline Students & \\
\hline International students & 166.3 \\
\hline Mainland students & 240.0 \\
\hline
\end{tabular}

Table 20. The average of data on summer/winter camp, summer/winter school

\begin{tabular}{|c|c|c|c|c|}
\hline Students & person & person & time & person each time \\
\hline International students & 0.4 & 10.4 & 27.7 & 1.7 \\
\hline Mainland students & 0.6 & 15.0 & 24.0 & 1.5 \\
\hline
\end{tabular}


Besides the English environment in summer/winter camps and schools, personal practice is another variable in this investigation. As shown in table 21, to a small extent, international students have more practice frequency than mainland students do, with around 4 times per month. As time went by, the difference gap increased until senior high school stage and then dipped slightly down in university stage, as shown in table 22-24. However, international students' amount of writing practice always outnumbered that of mainland students no matter in which period. At the university stage, the word account of the writing practice of two groups both augmented to over 350 words. Furthermore, international students wrote about 535 words for each homework, $46.2 \%$ more than mainland students (366 words). In view of selfpractice, although mainland students had advantages in primary school and junior high school, international students surpassed them in the last two stages.
It is worth mentioning that the collected data does not reflect the clear and absolute number because all figures are accurate to one decimal place, and some students forgot their practice frequency. For example, student I7 forgot his writing practice frequency for the junior high school stage, and for his senior high school stage, he wrote that his monthly writing practice time is variable. In this case, although student I7 filled the word count for writing practice and the number is calculated, his self-practice time is recorded as zero because the specific number is unknown. Besides, in the senior high school stage, student I16 only wrote his minimum writing words each time, and these data are selected and used when calculating average. This calculation method indicates that the real average from international students during junior and senior high school stage is higher than those shown in table 23 and 24.

Table 21. Average data of writing practice in primary school

\begin{tabular}{|l|l|l|l|}
\hline \multicolumn{1}{|c|}{ Average datalAverage times per month } & $\begin{array}{l}\text { Average words per time inAverage words per time in } \\
\text { homework } \\
\text { Students }\end{array}$ & 42.0 & 36.0 \\
\hline International students & 4.0 & 38.8 & 42.7 \\
\hline Mainland students & 3.8 & & \\
\hline
\end{tabular}

Table 22. Average data of writing practice in junior high school

\begin{tabular}{|c|c|c|}
\hline Students & Average times per month & $\begin{array}{l}\begin{array}{l}\text { Average words per time inAverage words per time in } \\
\text { homework }\end{array} \\
\text { self-practice }\end{array}$ \\
\hline International students & 7.3 & \begin{tabular}{|l|l}
107.0 & 91.3 \\
\end{tabular} \\
\hline Mainland students & 5.1 & 95.8 \\
\hline
\end{tabular}

Table 23. Average data of writing practice in senior high school

\begin{tabular}{|l|l|l|l|}
\hline \multicolumn{1}{|c|}{ Average datalAverage times per month } & $\begin{array}{l}\text { Average words per time inAverage words per time in } \\
\text { homework } \\
\text { Students }\end{array}$ & 135.1 & 121.0 \\
\hline International students & 10.8 & 117.7 & 109.8 \\
\hline Mainland students & 6.8 &
\end{tabular}

Table 24. Average data of writing practice in university

\begin{tabular}{|c|c|c|}
\hline Avera & Average times per month & $\begin{array}{l}\begin{array}{l}\text { Average words per time inAverage words per time in } \\
\text { homework }\end{array} \\
\text { self-practice }\end{array}$ \\
\hline International students & 5.8 & \begin{tabular}{|l|l|}
534.7 & 253.4 \\
\end{tabular} \\
\hline Mainland students & 2.5 & 225.3 \\
\hline
\end{tabular}

The last part of personalized data is about students traveling abroad experience. As shown in table 25, on average, international students tended to travel abroad more frequently and to stay abroad much longer than mainland students. Especially in terms of average days person, international students spent days (151.1 days) ten times more than mainland students did (15.2 days). For the average days of each person each time, the international students' data is over four times as many as that of mainland students. It is remarkable that student I16 spent more than four years abroad studying and traveling, whose data raised the average level of international students to a large degree. 
Table 25. Average data of travelling abroad

\begin{tabular}{|l|l|l|l|l|l|}
\hline \multicolumn{1}{|c|}{ Average data $\begin{array}{l}\text { Average } \\
\text { person }\end{array}$} & times & $\begin{array}{l}\text { per|Average } \\
\text { person }\end{array}$ & days & perAverage days per time & $\begin{array}{l}\text { Average days of each } \\
\text { person each time }\end{array}$ \\
\hline Students & 151.1 & 52.6 & 3.3 \\
\hline International students & 2.9 & 15.2 & 12.3 & 0.8 \\
\hline
\end{tabular}

\section{DISCUSSION}

As Guo et al. and Shi suggested, knowing more about English culture would help students reduce the Chinese negative transfer in English [5, 6]. Besides, Liu mentioned Tao Feng, who believed practice could help overcome the negative transfer of Chinese and "the negative transfer would be reduced or even be avoided" to some degree $[4,8]$. If the concept were correct, it could be inferred that the more knowledge about English culture and the more practice, the less negative transfer. However, the study among 32 students proves that the suggestions may not work as well as previously imagined.

Firstly, more immersion in the second-language education environment does not necessarily reduce negative transfer types. In total, 24 error types are calculated. Mainland students have 21 of them, and similarly, international students have 22 types. The comparison between these errors, which is made by only one student group, is shown in table 26. The first two columns are error types where international students have no errors, and the last three are error types where mainland students have no errors. Obviously, international students are not at an advantage over mainland students as international students have one more error type than mainland students.

Secondly, less immersion in the second-language education environment does not necessarily lead to the obvious increase of negative transfer amount. As shown in table 12 , mainland students have only $0.05 \%$ more frequency than international students on making errors. This figure means that in a 10,000-word passage, mainland students could probably make five more mistakes caused by Chinese negative transfer than international students. Even if this really happens, these five more errors do not mean the scarce capability as they are five errors in 10,000 words, but not 100 words.

Thirdly, more and less immersion in the secondlanguage education environment does not necessarily lead to a larger and smaller number of various sentence structures, but more immersion could lead to the use of various sentence structures more evenly. As shown in table 13-16, international and mainland students all use 16 kinds of sentence structures. However, for international students, as the range of the percentage of the number of appearances and the percentage of the most frequently used sentence structure are smaller compared with mainland students, it is suggested that international students tend to apply as many different sentence structures as possible in their passage. This may indicate that international students less prefer one particular sentence type and would like to enrich their English writing expressions.

Finally, more experience in English-teaching summer/winter camp/school, English writing practice, and travelling abroad may help reduce the effect of Chinese negative transfer. According to table 20, international students have slightly more days ( 0.2 day) on summer/winter camp/school. According to table 2124 , international students have more writing practice, a sum of the period from primary school to university. According to table 25, international students have traveled abroad more frequently and spent much longer time abroad. Combined with data in table 12, which show that international students have less error frequency, it is inferred that more experience in second-language environment and practice may help reduce Chinese negative transfer.

Table 26. Errors made by only one student group

\begin{tabular}{|c|c|c|c|c|c|}
\hline $\begin{array}{l}\text { Average dat } \\
\text { Students }\end{array}$ & $\begin{array}{l}2.6 \text { other } \\
\text { forms }\end{array}$ & wrong7.2 inversion & Punctuation & $\begin{array}{l}\text { 4. adverb } \\
4.1 \text { coordinate with } \\
\text { noun }\end{array}$ & 10.1 -ing perticiple \\
\hline $\begin{array}{l}\text { International } \\
\text { students }\end{array}$ & 0 & 0 & 2 & 1 & 1 \\
\hline Mainland students & 1 & 2 & 0 & 0 & 0 \\
\hline
\end{tabular}

\section{CONCLUSION}

Although the difference of writing practice word account between international and mainland students is large, the discrepancy of average days each person each time on English-teaching summer/winter camp/school and error frequency is relatively smaller. As the representation of the influence of Chinese negative transfer, the error frequency does not show great difference under the facts, the effectiveness of the suggestions and strategies, such as knowing more about English culture and practice more, have been called into 
question. Thus, it is more proper to conclude that the extra English learning experiences reduce negative transfer in syntactical patterns among Chinese students' writing in SLA limitedly.

\section{REFERENCES}

[1] Jarvis, S., \& Pavlenko, A. (2008). Crosslinguistic influence in language and cognition. Routledge.

[2] Perkins, D. N., \& Salomon, G. (1992). Transfer of learning. International encyclopedia of education, 2 , 6452-6457.

[3] Odlin, T. (2005). Crosslinguistic influence and conceptual transfer: what are the concepts?. Annual Review of Applied Linguistics, 25, 23. doi:10.1017/ S0267190505000012.

[4] Liu, Z. (2011). Negative transfer of Chinese to college students ${ }^{\text {ee }}$ English writing. Journal of
Language Teaching and Research, 2(5). https://doi.org/10.4304/jltr.2.5.1061-1068

[5] Guo, M., Liu, J., \& Chen, P. (2014). A case study on the effect of Chinese negative transfer on English writing. Theory and Practice in Language Studies, 4(9). https://doi.org/10.4304/tpls.4.9.1941-1947

[6] Shi, W. (2015). Types of Chinese negative transfer to English learning and the countermeasures. Theory and Practice in Language Studies, 5(6), 1226. https://doi.org/10.17507/tpls.0506.15

[7] Chan, A. Y. (2004). Syntactic Transfer: Evidence from the interlanguage of Hong Kong Chinese ESL learners. The Modern Language Journal, 88(1), 5674. https://doi.org/10.1111/j.00267902.2004.00218.x

[8] Tao Feng. (2005). The effect and responding strategy of Chinese negative transfer on English writing. Basic English Education 16.4, 32-35. 